\title{
WDR5 high expression and its effect on tumorigenesis in leukemia
}

\author{
Zheng Ge ${ }^{1,2,3}$, Evelyn J. Song ${ }^{2}$, Yuka Imamura Kawasawa4, Jianyong Li³, Sinisa \\ Dovat $^{2}$, Chunhua Song ${ }^{2}$ \\ ${ }^{1}$ Department of Hematology (Key Department of Jiangsu Medicine), Zhongda Hospital, Southeast University Medical School, \\ Nanjing, Jiangsu, China \\ ${ }^{2}$ Department of Pediatrics, Pennsylvania State University College of Medicine, Hershey, PA, USA \\ ${ }^{3}$ Department of Hematology, The First Affiliated Hospital of Nanjing Medical University, Jiangsu Provincial Hospital, Nanjing, \\ China \\ ${ }^{4}$ Pennsylvania State Hershey Genome Sciences Facility, Pennsylvania State College of Medicine, Hershey, PA, USA \\ Correspondence to: Chunhua Song, email: csong@hmc.psu.edu \\ Sinisa Dovat, email: sdovat@hmc.psu.edu \\ Jianyong Li, email: lijianyonglm@medmail.com.cn
}

Keywords: WDR5, H3K4me3, MLL, leukemia

Received: March 16, 2016

Accepted: April 27, 2016

Published: May 12, 2016

\begin{abstract}
WD repeat domain 5 (WDR5) plays an important role in various biological functions through the epigenetic regulation of gene transcription. However, the oncogenic effect of WDR5 in leukemia remains largely unknown. Here, we found WDR5 expression is increased in leukemia patients. High expression of WDR5 is associated with high risk leukemia; Patients with WDR5 and MLL1 high expression have poor complete remission rate. We further identified the global genomic binding of WDR5 in leukemic cells and found the genomic co-localization of WDR5 binding with H3K4me3 enrichment. Moreover, WDR5 knockdown by shRNA suppresses cell proliferation, induces apoptosis, inhibits the expression of WDR5 targets, and blocks the H3K4me3 enrichment on the promoter of its targets. We also observed the positive correlation of WDR5 expression with these targets in the cohort study of leukemia patients. Our data reveal that WDR5 may have oncogenic effect and WDR5-mediated H3K4 methylation plays an important role in leukemogenesis.
\end{abstract}

\section{INTRODUCTION}

Genetic and epigenomic regulation play key roles in hematopoietic homeostasis, the alterations in epigenome and abnormality in enzymatic processes that control epigenomic function are frequently associated with leukemia [1-4]. It is reported that the histone H3Lys4 (H3K4)-methyl epigenome regulates leukemia stem cell oncogenic potential ${ }^{2}$. Mixed-lineage Leukemia (MLL) is a pro-oncoprotein and forms a SET1-like histone methyltransferase complex in leukemia. $M L L$ amplification plays an important role in leukemogenesis [3-8]. As leukemia drivers, $M L L$ rearrangements result in the fusion of the mixed lineage leukemia gene with other genes, and are one of the most important high-risk leukemia markers $[3,9]$. One $M L L 1$ allele is truncated and fused in frame with over 70 partners to produce oncogenic $M L L 1$ fusion proteins [10-12]; and these fusion proteins stimulate transcription by different mechanisms [13-19]. With rare exception [20], one common feature of the $M L L 1$ abnormality in leukemia is the preservation of at least one wild-type $M L L 1$ allele with the intact SET domain [21]. This finding suggested that MLL1 rearrangement has the limited impact on $\mathrm{H} 3 \mathrm{~K} 4 \mathrm{me} 3$ level in the leukemic cells, and also H3K4 trimethylation may have more profound effect on oncogenesis in patients with MLL1 rearrangements.

MLL core complex including MLL, WD repeat domain 5 (WDR5), Retinoblastoma-binding protein 5 (RbBP5), and (absent, small, or homeotic)-like (Drosophila) (ASH2) is required for maximal enzymatic activity $[22,23]$. WDR5 mediates interaction of the MLL catalytic unit with the core complex and the histone H3 substrate [24]. WDR5 prefers to bind dimethylated H3K4 peptide [25]. WDR5 itself is central for complex assembly and catalyzing H3K4 trimethylation activity [26-28]. These findings indicate that WDR5 is critical for H3K4 methylation. However, the global correlation of WDR5 with $\mathrm{H} 3 \mathrm{~K} 4 \mathrm{me} 3$ in leukemia cells has yet been determined. 
WDR5 interacts with MLL through the Win motif $[29,30]$. Recently it is reported that specifically blocking the MLL1-WDR5 interaction using the inhibitor MM401 prevents MLL1-WDR5 complex assembly and inhibits MLL1 activity [31]. This inhibitor also blocks proliferation of MLL cells by inducing cell-cycle arrest, apoptosis, and myeloid differentiation; and it induces changes in gene expression similar to those of MLL1 deletion. Similarly, another MLL-WDR5 interaction blocker shows selectively inhibited proliferation and induced differentiation in p30-expressing human AML cells [32]. These reports not only support the key role of MLL1 activity in regulating MLL1-dependent leukemia transcription program but also indicate that WDR5 exerts its role mainly by forming a complex with MLL in leukemia cells.

WDR5 is also reported to be overexpressed in other cancers. WDR5 is hyperexpressed and critical for cell proliferation and H3K4 methylation in human neuroblastoma, prostate cancers and bladder cancers [33-36]. However, very little is known about the role of WDR5 in leukemia, despite our growing knowledge about MLL1 fusion proteins and leukemia. Here, we reported the WDR5 high expression in human acute leukemia and WDR5-mediated $\mathrm{H} 3 \mathrm{~K} 4$ methylation of oncogenic targets may play an important role in leukemogenesis.

\section{RESULTS}

\section{Association of WDR5 expression with features of adult ALL}

We detected WDR5 mRNA expression in 60 newly diagnosed adult ALL (20 T-ALL and 40 B-ALL) patients, respectively. We found that WDR5 is significantly more expressed in patients compared to normal controls (Figure 1A), and no significant difference between T-ALL and B-ALL (data not shown). Patients with ALL were divided into high (45 cases) and low (15 cases) WDR5 expression groups. Patients with high expression of WDR5 have higher percentage of CD20+ cells $(60.0 \%$ vs $0.0 \%, P=0.001)$, Philadelphia chromosome $(\mathrm{Ph})(+)(34.4 \%$ vs $0.0 \%, P=0.026)$, higher $M L L 1$ expressions (66.7\% vs $13.3 \%, P=0.000)$, splenomegaly and liver infiltration $(72.4 \%$ vs $20.0 \%$, $P=0.001 ; 51.7 \%$ vs $13.3 \%, P=0.013)$, and leukemia blast in bone marrow (BM) $(87.6 \%$ vs $72.4 \%, P=0.022)$ compared to patients with low WDR5 expression (Figure 1B, 1C and 1D; Supplementary Table S1). No significant differences in WDR5 expression are observed with age, sex, and peripheral blood blasts. These data indicate that high expression of WDR5 is associated with proliferation and high-risk ALL, suggesting its role in leukemogenesis of ALL.

\section{Association of $W D R 5$ expression with characteristics of adult AML}

We also detected WDR5 mRNA expression in 88 newly diagnosed adult AML patients. We found that WDR5 is significantly higher expressed in AML patients compared to normal control (Figure 1A). Patients were divided into high (27 cases) and low (61 cases) WDR5 expression groups. Compared to low WDR5 expression, patients with its high expression showed high median BM blasts $(90.8 \%$ vs $77.9 \%, P=0.008)$ and peripheral blood blast $(81.5 \%$ vs $66.5 \%, P=0.049$ ) (Figure 1E, Supplementary Table S2). Similar as ALL, we also observed higher MLL1 expression in WDR5 high expression group (85.2\% vs $31.1 \%, P<0.001$ ) (Figure $1 F$, Supplementary Table S2). Importantly, when looking at risk status of patients with WDR5 expression, we found that the favorable-risk is significantly lower in WDR5 high expression patients $(22.2 \%$ vs $54.7 \%, P=0.016)$, while intermediate-risk and poor-risk are much higher in the high group than that of the low group $(70.4 \%$ vs $43.4 \%, P<0.001 ; 7.4 \%$ vs $1.9 \%, P<0.001$ ). (Figure $1 \mathrm{G}$, Supplementary Table S2). No significant differences in WDR5 expression were observed with age, sex and $\mathrm{WBC}$. These data indicate that high expression of $W D R 5$ is associated with high-risk AML, further indicated its oncogenic effect on AML.

\section{Association of $W D R 5$ high expression with $M L L 1$ high expression in leukemia cells}

We also analyzed the MLL1 expression with WDR5 expression in ALL and AML patients. We found that high WDR5 expression is significantly associated with high $M L L 1$ expression in ALL and AML patients (Figure $1 \mathrm{~B}$ and $1 \mathrm{~F}$, Supplementary Tables S1 and S2). We also observed that MLL1 high expression has higher percentage of CD20+ cells, splenomegaly and liver infiltration compared to patients with low WDR5 expression in ALL (Supplementary Table S1). MLL1 high expression also showed high median bone marrow blasts and significantly higher percentage of intermediate-risk and poor-risk but lower favorable-risk in AML patients (Supplementary Table S2). We further analyzed the clinical features of the patients with both WDR5 and MLL1 high expressions $\left(W D R 5^{\text {high }} M L L^{\text {high }}\right.$ ) in the ALL and AML patients. We found that ALL patients with $W D R 5^{\text {high }} M L L^{\text {high }}$ showed higher percentage of $\mathrm{Ph}+$ chromosome $(35 \%$ vs $0 \%, P=0.027)$, CD20(+) cells $(64.7 \%$ vs $0 \%, P=0.002)$, splenomegaly and liver infiltration $(76.5 \%$ vs $15.4 \%, P=0.003 ; 58.8 \%$ vs $0 \%, P=0.001$ ) (Figure $2 \mathrm{~A}$ and $2 \mathrm{~B}$; Supplementary Table S3), and also higher median percentage of BM blasts $(87.8 \%$ vs $62.0 \%, P=0.011)$ than the $W D R 5^{\text {low }} M L L^{\text {low }}$ expression group (Supplementary Table S3). Particularly, the percentage of the period achieving complete remission 


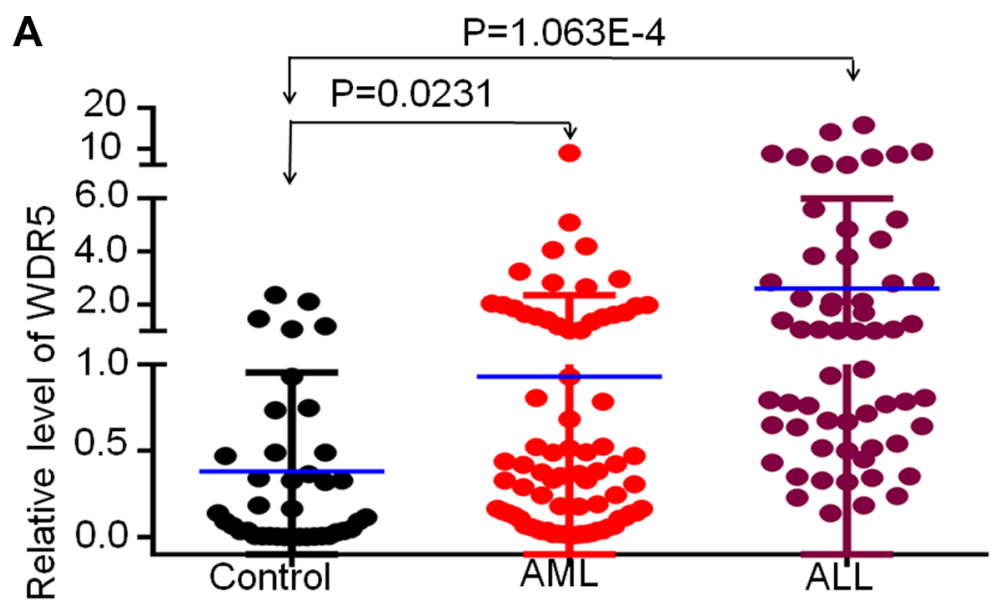

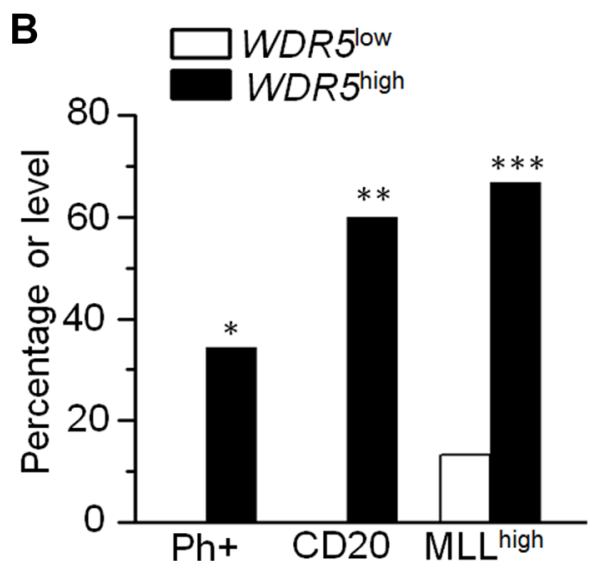

$(+)$
C

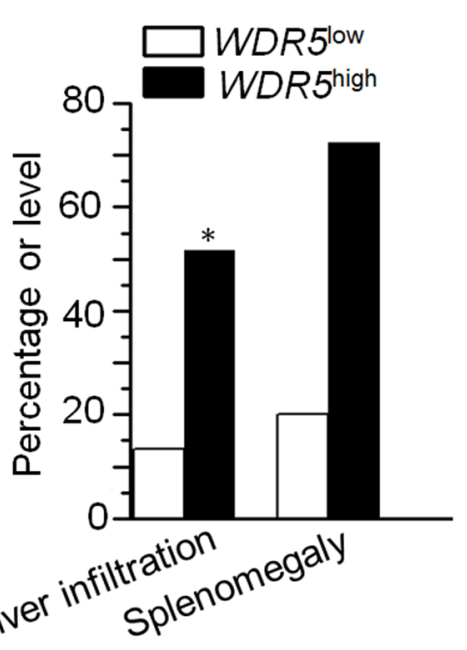

D

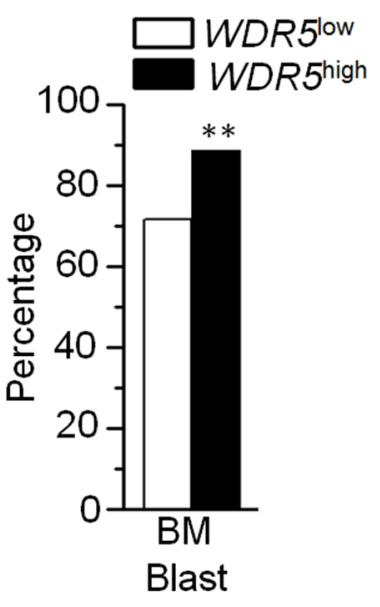

$\mathbf{E}$

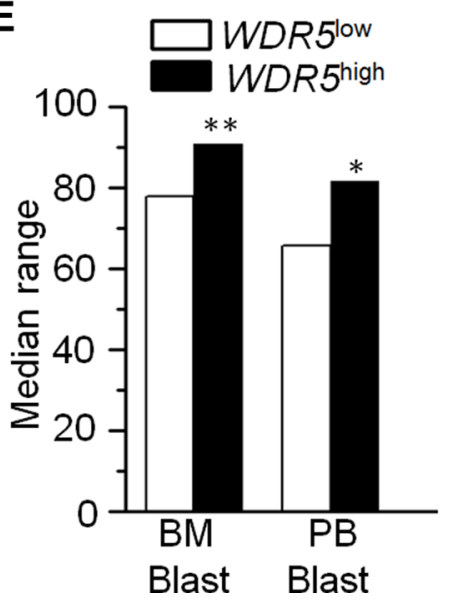

$\mathbf{F}$

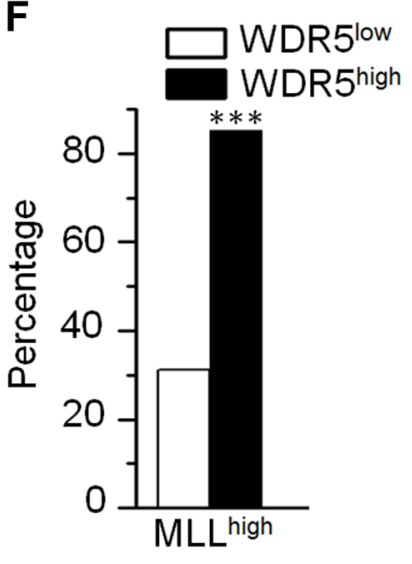

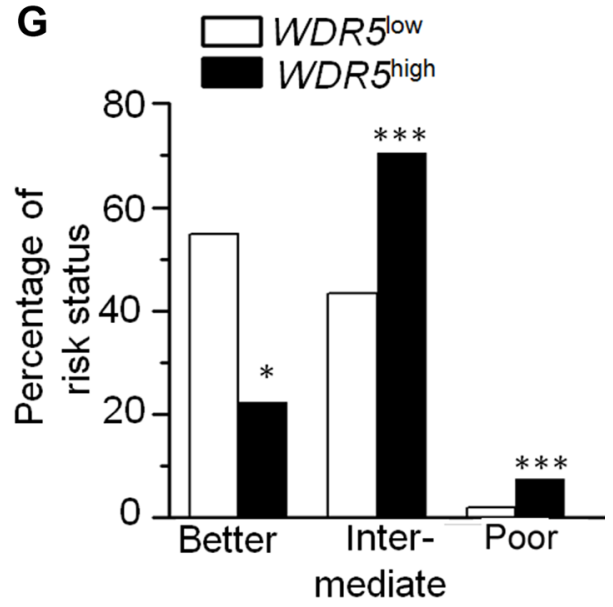

Figure 1: WDR5 expression in AML and ALL and its correlation with clinical features. (A) WDR5 expression in ALL and AML. WDR 5 was detected by qPCR in ALL and AML patients' samples and compared to normal bone marrow tissue (control). The relative level of WDR 5 mRNA was calculated by standard curve. The difference of the WDR5 expression was analyzed with student $t$-test. $P<$ 0.05 are considered as significant. (B-D): Correlation of WDR5 high and low expression with clinical features in patients with ALL. (E-G) Correlation of WDR5 high and low expression with clinical features in patients with AML. $* P<0.05 ; * * P<0.01 ; * * * P<0.0001$. 
(CR) more than 4 weeks in the ALL patients with $W D R 5^{\text {high }} M L L^{\text {high }}$ was significantly higher than that of $W D R 5^{\text {low }} M L L^{\text {low }}$ expression $(53.6 \%$ vs $16.7 \%, P=0.03$ ) (Figure $2 \mathrm{C}$ ). AML patients with $W D R 5^{\text {high }} M L L^{\text {high }}$ showed higher median percentage of bone marrow blasts $(90.0 \%$ vs $68.5 \%, P=0.004)$ than the $W D R 5^{\text {low }} M L L 1^{\text {low }}$ expression group (Figure 2D, Supplementary Table S3). Based on the cytogenetics of AML patients, the risk status was divided into favorable-risk, intermediate-risk and poor-risk. The risk status analysis data showed that AML patients with $W D R 5^{\text {high }} M L L^{\text {high }}$ had significantly higher percentage of intermediate-risk and poor-risk $(73.9 \%$ vs $37.1 \%, P<$ $0.001 ; 4.3 \%$ vs $0.0 \%, P<0.001)$ but lower percentage of favorable-risk $(21.7 \%$ vs $62.9 \%, P=0.006)$ (Figure 2E; Supplementary Table S3).

Further, we observed that MLL1 and WDR5 are expressed in leukemia cells (Supplementary Figure S1A). With co-immunoprecipitation assay, we also showed that MLL1 and WDR5 interact in the leukemia cells (Supplementary Figure S1B). These data suggested that WDR5 high expression-induced leukemogenesis may be mediated by interaction with MLL1 in the cells.

\section{WDR5 knockdown results in inhibition of cell proliferation and apoptosis}

Next, we explored the effect of WDR5 knockdown in cell growth of leukemia cells. With WST-1 cell proliferation assay, we found that WDR 5 knockdown with shRNA significantly suppress the proliferation of Nalm6 and U937 cells compared to that of scramble shRNA control (siCTL) (Figure 3A and 3B). We also observed the effect of WDR5 knockdown on apoptosis of the cells. Figure $3 \mathrm{C}$ is the flow cytometry chart for the apoptosis assay in Nalm6 cells. The quantitative data showed that WDR5 shRNA significantly increases the apoptosis of Nalm6 and U937 cells compared to control (Figure 3D). These data revealed that WDR5 is essential for the cell growth of the leukemia cells, further suggesting the oncogenic role of WDR5 in leukemia.

\section{Genome-wide targeting of WDR5 in leukemia cells}

We determined the genome-wide occupancy of WDR5 and using chromatin immunoprecipitation followed by deep-sequencing (ChIP-seq) in human RS4;11 ALL and THP-1 AML leukemia cells, we identified 1490 and 515 target genes for WDR5 in RS4;11 and THP-1 cells, respectively. ChIP-seq data for WDR5 were validated by quantitative chromatin immunoprecipitation (qChIP) analysis of the high and low rank ChIP-seq peak values (data not shown).

Analysis of the distribution of WDR5 peaks in genomic regions showed that more than half of WDR5 peaks are located in intergene regions and about $5-6 \%$ of peaks are in promoter and enhancer regions (Figure 4A). We also did the analysis of GO term and pathways in the gene targets, and found the WDR5 binding genes are involved in multi-oncogenic signaling, apoptosis, transcriptional regulation, histone modification, cell proliferation and apoptosis, cell adhesion and metabolism, etc. (Supplementary Figure S1C).

We further observed WDR5 binding on its targets in ALL and AML cell lines by qChIP. WDR5 significantly binds to promoter region of Tyrosine-protein kinase Lyn (Lyn), B-cell CLL/lymphoma 9 (BCL9), Ras-related protein Rab-28 (RAb28), Cluster of Differentiation 93 (CD93), Mediater complex subunit 24 (MED24) and RBM22 in Nalm6 B-ALL cells (Figure 4B) and U937 AML cells (Figure 4C). Importantly, WDR5 also significantly binds to these target genes in primary B-ALL (Figure 4D) and AML (Figure 4E) cells.

\section{Global association of WDR5 peaks and H3K4me3 peaks in leukemia cells}

It is reported that the inhibitors blocking WDR5MLL1 interaction affects the global H3K4me3 level in leukemic cells [31,32], however it has no report about global correlation of WDR5 binding with H3K4me3 binding targets. To provide insights into the epigenetic mechanisms that determine expression of WDR5 target genes in the cells, we identified the H3K4me3 binding profiling in RS4;11 and THP-1 cells by ChIP-seq. The distribution of $\mathrm{H} 3 \mathrm{~K} 4 \mathrm{me} 3$ peaks in genomic regions is showed on Supplementary Figure S2. We also analyzed the distribution of $\mathrm{H} 3 \mathrm{~K} 4 \mathrm{me} 3$ peaks relative to WDR5 peaks and found that WDR5 peaks are enriched with the presence of $\mathrm{H} 3 \mathrm{~K} 4 \mathrm{me} 3$ peaks (Figure $5 \mathrm{~A}$ ). We further observed the obvious reduction of $\mathrm{H} 3 \mathrm{~K} 4 \mathrm{me} 3$ level in both Nalm6 and U937 cells upon WDR5 knockdown compared to that in scramble shRNA control (Figure 5B). These data indicated that WDR5 not only associates with $\mathrm{H} 3 \mathrm{~K} 4 \mathrm{me} 3$ but also affects $\mathrm{H} 3 \mathrm{~K} 4 \mathrm{me} 3$ generation in the cells. We also observed that WDR 5 and $\mathrm{H} 3 \mathrm{~K} 4 \mathrm{me} 3$ peaks are simultaneously presented in the promoter region of WDR5 targets using genome browser (Supplementary Figure S3). These data indicate that WDR5 is essential for the $\mathrm{H} 3 \mathrm{~K} 4$ methylation on the promoter of its targets. Then, we further observed the enrichment of H3K4me3 in the promoter region of WDR5 targets and found that $\mathrm{H} 3 \mathrm{~K} 4 \mathrm{me} 3$ is dramatically enriched in the promoter region of Lyn, BCL9, RAB28, CD93, MED24, and RBM22 in Nalm6 (Figure 5C) and U937 (Figure 5D) cells as well as primary B-ALL (Figure 5E) and AML (Figure 5F) cells.

\section{WDR5 controls the expression of its targets}

We analyzed the correlation of WDR5 expression with that of its targets in the cohort study of ALL and AML patients, and observed a positive correlation of WDR5 
expression with that of Lyn (Supplementary Figure S4A and S4B), MED24 (Supplementary Figure S4C and S4D), RBM22 (Supplementary Figure S4E and S4F), which are important for oncogenesis and apoptosis. To further assess the effect of WDR5 on expression of the target genes, Nalm6 and U937 cells were expressed with WDR5 shRNA or control scramble shRNA. Reduced WDR5 expression resulted in reduced transcription of WDR5 target genes-Lyn, BCL-9, RAB28, CD93, MED24 and RBM22 (Figure 6A and 6B). Reduced expression of Lyn and BCL9 was also observed in the WDR5 knockdown RS4;11 and THP- 1 cells (Supplementary Figure S5A and S5B). Moreover, WDR5 knockdown obviously reduced the WDR5 binding to the promoter of its targets, Lyn, BCL9 and RBM22 (Supplementary Figure S6). This data indicate that WDR5 is responsible for transcription of these genes and suggest that WDR5 promotes leukemia via transcriptional activation of genes.

\section{WDR5 is essential for $\mathrm{H} 3 \mathrm{~K} 4 \mathrm{me} 3$ enrichment in the promoter of its targets}

We further analyzed the WDR5 dependence of $\mathrm{H} 3 \mathrm{~K} 4 \mathrm{me} 3$ enrichment in the promoter of its targets. WDR 5 was knocked-down by shRNA in Nalm6 and U937 cells. The enrichment of $\mathrm{H} 3 \mathrm{~K} 4 \mathrm{me} 3$ in the promoter region of Lyn and BCL9 was determined by qChIP. Figure 6C showed the location of the primers that we used for PCR of the genes in the ChIP'd DNAs. WDR5 knockdown blocks the $\mathrm{H} 3 \mathrm{~K} 4 \mathrm{me} 3$ enrichment in the promoter region of WDR5 targets -Lyn and BCL9 (Figure 6D-6G). Similar results are observed in MLL-rearranged RS4;11 and THP-1 cells (Supplementary Figure S5C and S5D). These data indicate that WDR5 is essential for histone 3 lysine 4 methylation in the promoter region of its targets, and also suggest that WDR5 activates gene expression via increasing $\mathrm{H} 3 \mathrm{~K} 4 \mathrm{me} 3$ levels of the genes.
A

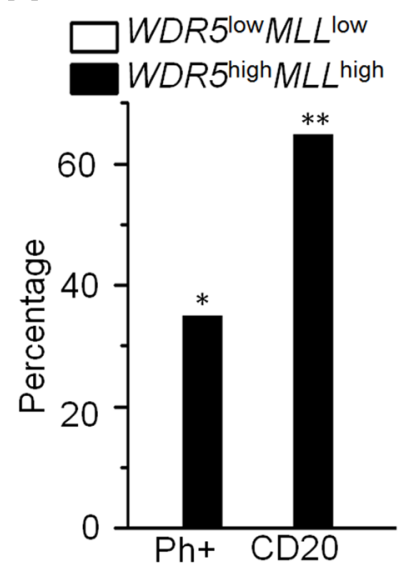

$(+)$
B

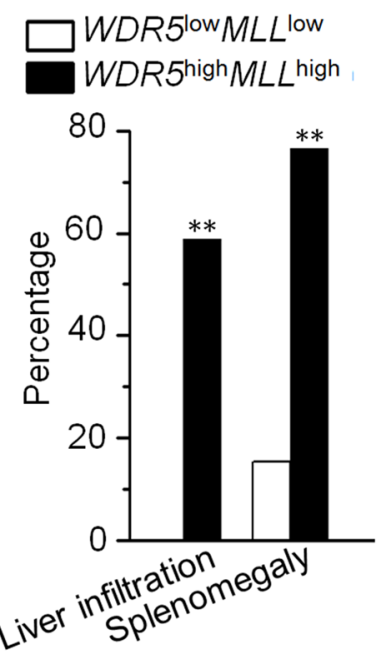

C
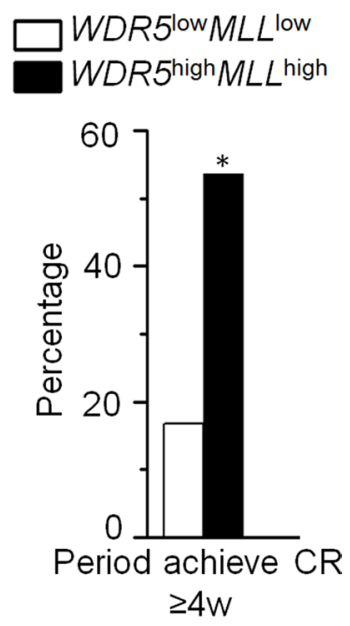

D
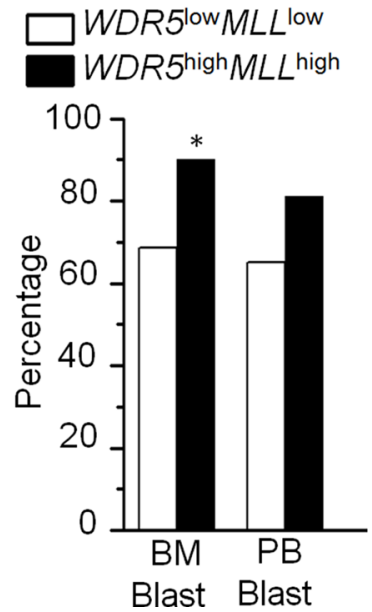

E

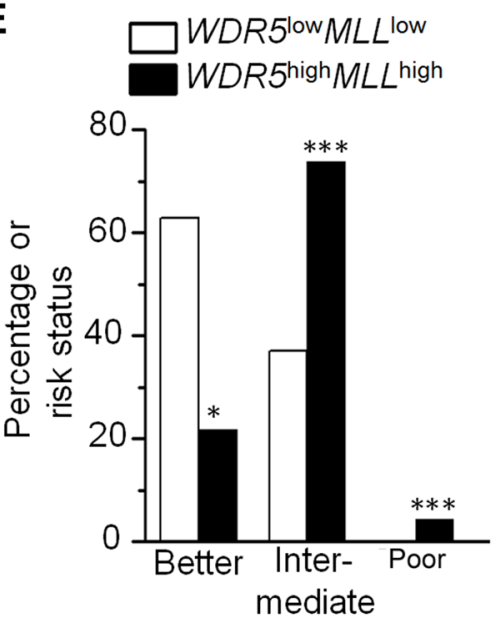

Figure 2: Clinical features of patients with $\boldsymbol{W D R} 5^{\text {high }} \boldsymbol{M L} \boldsymbol{L}^{\text {high }}$ in ALL and AML. (A-C) Comparison of clinical features of ALL patients with $W D R 5^{\text {high }} M L L^{\text {high }}$ to that with $W D R 5^{\text {low }} M L L^{\text {low }}$. (D-E) Comparison of clinical features in AML patients with $W D R 5^{\text {high }} M L L^{\text {high }}$ to that with $W D R 5^{\text {low }} M L L^{\text {low }} * P<0.05 ; * * P<0.01 ; * * * P<0.0001$. 


\section{DISCUSSION}

There is no report about WDR5 expression and its correlation with clinical features in leukemia.

Our data first showed the WDR5 high expression particularly the $\mathrm{WDR} 5^{\text {high }}+\mathrm{MLL} 1^{\text {high }}$ expression in leukemia patients and their correlations with high-risk ALL and AML leukemia; and revealed the oncogenic effects of high WDR5 expression in acute leukemia by activation of its oncogenic targets via epigenomic regulation, as shown on a model of Supplementary Figure S7.

\section{Oncogenic effect of WDR5 high expression}

The crystal structural analysis suggests that WDR5 has many exposed surfaces which make it a perfect adaptor to interact with other proteins. It has been shown that WDR5 prefers to bind dimethylated histone H3Lys4 peptide [25]. We observed the co-localization of WDR5 binding with $\mathrm{H} 3 \mathrm{~K} 4 \mathrm{me} 3$ globally. WDR5 knockdown results in the cell proliferation arrest and apoptosis in leukemic cells, and induces suppression of expression of its targets and loss of H3K4me 3 enrichment in the promoter region of the targets. Clinical cohort data also showed that WDR5 expression is positively correlated with the oncogene Lyn, RAB28 (data not shown), and anti-apoptotic factor BCL9. These data reveal that WDR5 may have an oncogenic effect in leukemia.
Moreover, WDR5 functions as a common subunit of all six mammalian histone H3Lys4 methyltransferases $[37,38]$. MLL1 protein also interacts with WDR5 by Win motif next to the SET domain $[29,30]$. We also found that WDR5 is associated with MLL1 in the leukemia cells. WDR5 knockdown induces the reduction of H3K4me3 level. Clinical data showed that ALL and AML patients with $W D R 5^{\text {high }} M L L^{\text {high }}$ have high-risk leukemia or are in high-risk status. These data indicate that WDR5 could exert its oncogenic effect mainly by recruitment of MLL1 to increase $\mathrm{H} 3 \mathrm{~K} 4 \mathrm{me} 3$ levels in the promoter region of its targets. This would further result in the activation of oncogenic signaling, even in $M L L$ rearrangement patients, although it is also reported that WDR5 itself is central for complex assembly and catalyzing $\mathrm{H} 3 \mathrm{~K} 4$ trimethylation activity [26-28].

\section{A novel oncogenic mechanism in ALL and AML with MLL rearrangement}

MLL rearrangement occurs in approximately $10 \%$ of human acute leukemia, and are present in $>70 \%$ of infant ALL cases, $35-50 \%$ of infant AML cases and secondary or therapy-related leukemia $[3,9]$. In the most common MLL1 rearrangements, the MLL1 allele is truncated and fused in frame with over 70 partners to produce oncogenic MLL1 fusion proteins (e.g., MLL-AF9, MLL-ENL) [10-12]. Previous work has shown that some MLL1
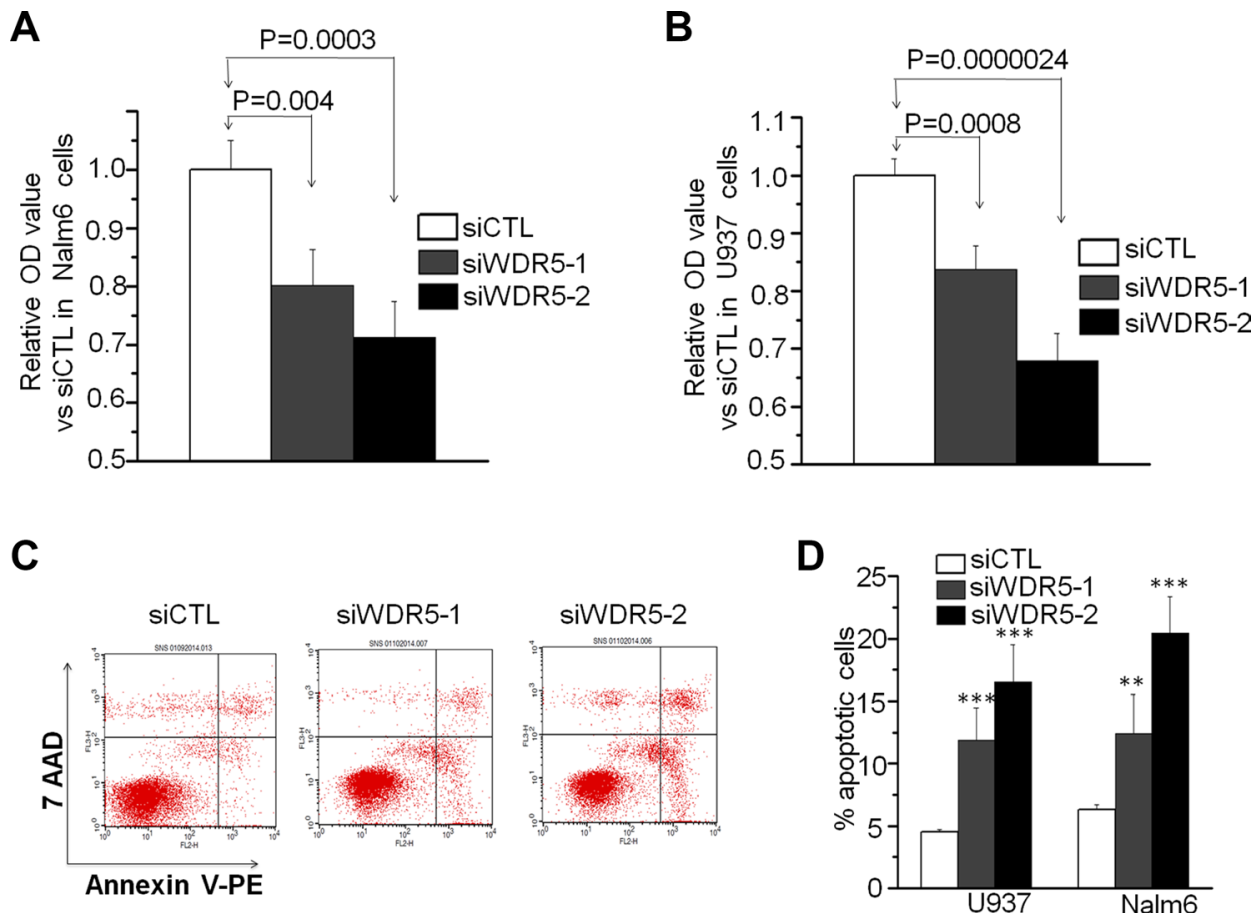

Figure 3: WDR5 knockdown induces proliferation arrest and cell apoptosis in ALL and AML cells. (A-B) WDR5 knockdown induced the proliferation arrest in Nalm6 B-ALL (A) and U937 AML (B) cells. siWDR5-1=WDR5 shRNA \#1, siWDR5$2=$ WDR 5 shRNA \#2; siCTL=scramble shRNA. $P<0.05$ are considered as significant. $(\mathbf{C}$ and $\mathbf{D})$ WDR5 knockdown increased the apoptotic cell rate in the cells. $\mathrm{C}$ is the representative flow data in Nalm6 cells. D is the quantitation data in Nalm6 and U937 cells. $* * P<0.01$; $* * * P<0.0001$. 
fusion proteins, especially those forming the EAP complex [13], are recruited to Hoxa9 and directly stimulate transcription elongation by recruiting cofactor complexes such as PAF1C [14, 15], DOT1L [16-18], and pTEFb/ BRD4 [19]. We observed many H3K4me3 binding sites in the MLL1 rearrangement cell lines, and also showed that WDR5 globally co-localizes with H3K4me3. WDR5 knockdown results in a significant decrease of $\mathrm{H} 3 \mathrm{~K} 4 \mathrm{me} 3$ enrichment in the promoter region of its targets in both the cells without MLL rearrangement (Nalm6 and U937 cells) as well as that with ML11 rearrangement (RS4;11 and THP-1 cells). We also observed that WDR5 is highly expressed in acute ALL and AML, and high expression of both $W D R 5$ and $M L L$ are correlated with high risk-ALL and -AML. Our findings revealed that high expression of WDR5, a key member of the MLL complex, is the novel mechanism responsible for oncogenesis in ALL and AML by increasing Histone H3 Lys4 methylation on its oncogenic gene targets in patients with or without MLL rearrangement. High expression of WDR5 results in the enrichment of $\mathrm{H} 3 \mathrm{~K} 4 \mathrm{me} 3$ in the promoter region of its targets by increasing recruitment of MLL1 methyltransferase. In cells with MLL1 rearrangement, high expression of WDR 5 induces the enrichment of $\mathrm{H} 3 \mathrm{~K} 4 \mathrm{me} 3$ on its targets by recruiting more wild type MLL1 and through the methyltransferase activity of WDR5 itself.

\section{WDR5 targets responsible for its oncogenic effect}

It is reported that WDR5 drives the expression of protumorigenic gene-MDM2 with c-MYC in neuroblastoma [35]; WDR5 high expression promotes proliferation,
A

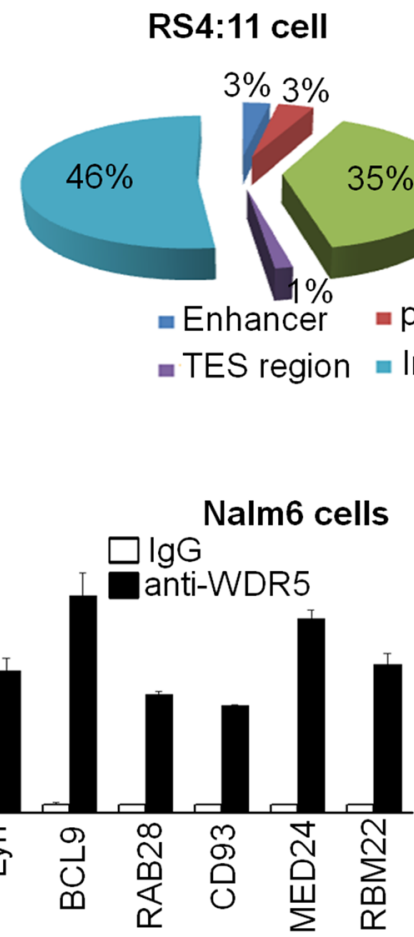

D

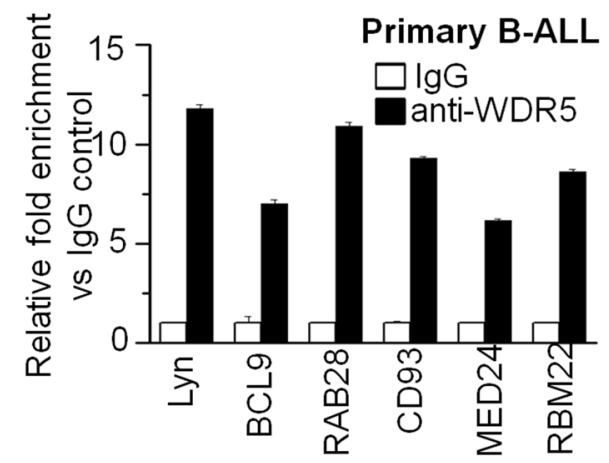

C

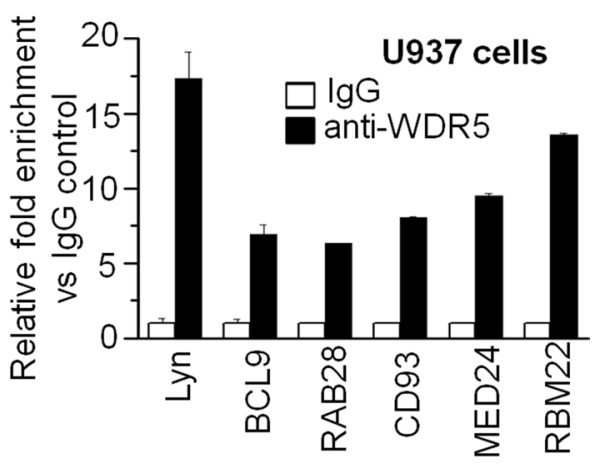

$\mathbf{E}$

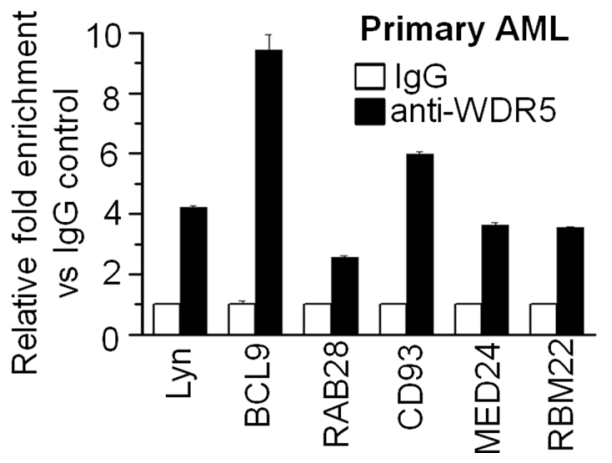

Figure 4: Genome-wide distribution of WDR5 and Gene Ontology (GO) analysis. (A) Percentages of peaks that bind sites in each location are given. (B-E) qChIP data showed that WDR5 binds to the promoter region of its targets identified by ChIP-seq in leukemic cell lines-Nalm6 (B) and U937 cells (C) as well as primary B-ALL (D) and AML (E). 
self-renewal and chemoresistance in bladder cancer via mediating $\mathrm{H} 3 \mathrm{~K} 4$ trimethylation on cell cycle genes such as CCNA, CCNB1, CCND1, CCNE1 etc. [36]; Also it has reports that blocking of MLL-WDR5 interaction and MLL1 knockdown induced the suppression of c-MYC and BCL-2 in leukemia cells [27]; and loss of WDR5 increases expression of G-CSF, ccl9, etc., and restores granulocytic differentiation potential in $\mathrm{C} / \mathrm{EBPa} \mathrm{p} 30$-expressing AML cells [32]. However, it has no report about the WDR5 global

A

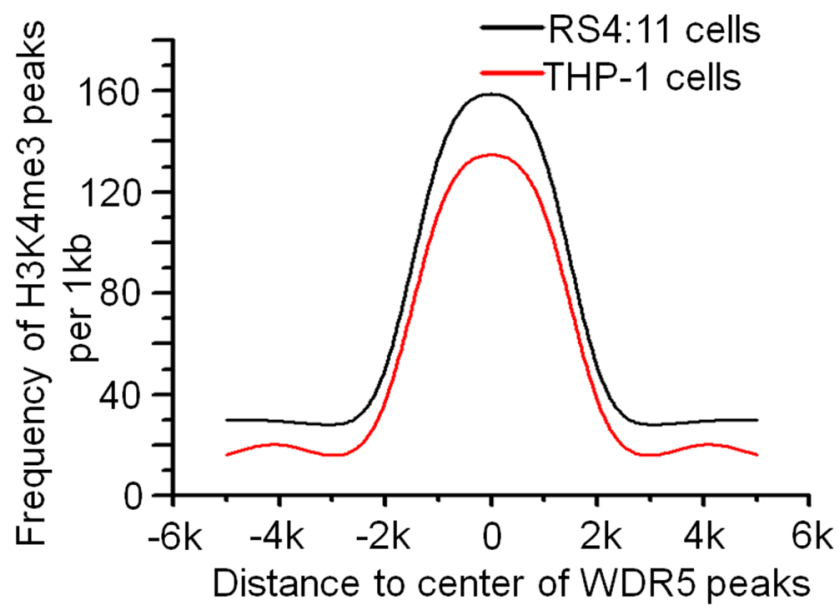

C

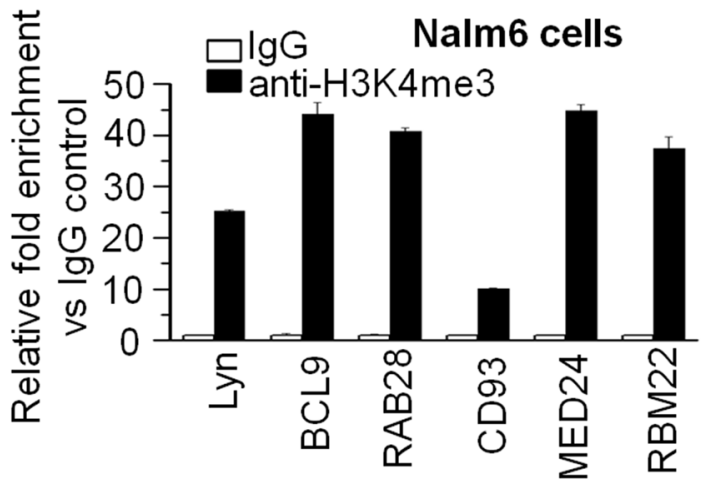

E

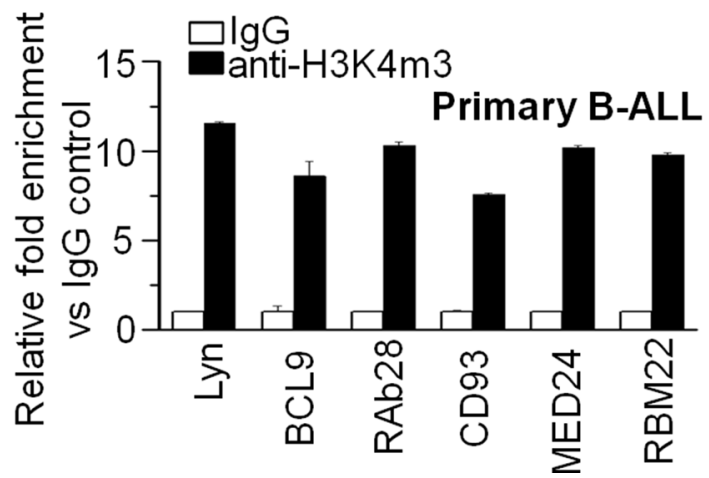

binding gene targets in leukemia cells. Here, we identified around 2000 WDR5 binding genes, and GO term analysis showed that these genes are involved in biological functions such as transcriptional regulation, chromatin remodeling, multi-oncogenic pathways, apoptosis regulation, metabolism, cell adhesion, and etc.

Lyn, a gene target of WDR5, is a tyrosine kinase belonging to the Src family kinases (SFKs) and plays a crucial role in the onset and progression of CLL [39-42].
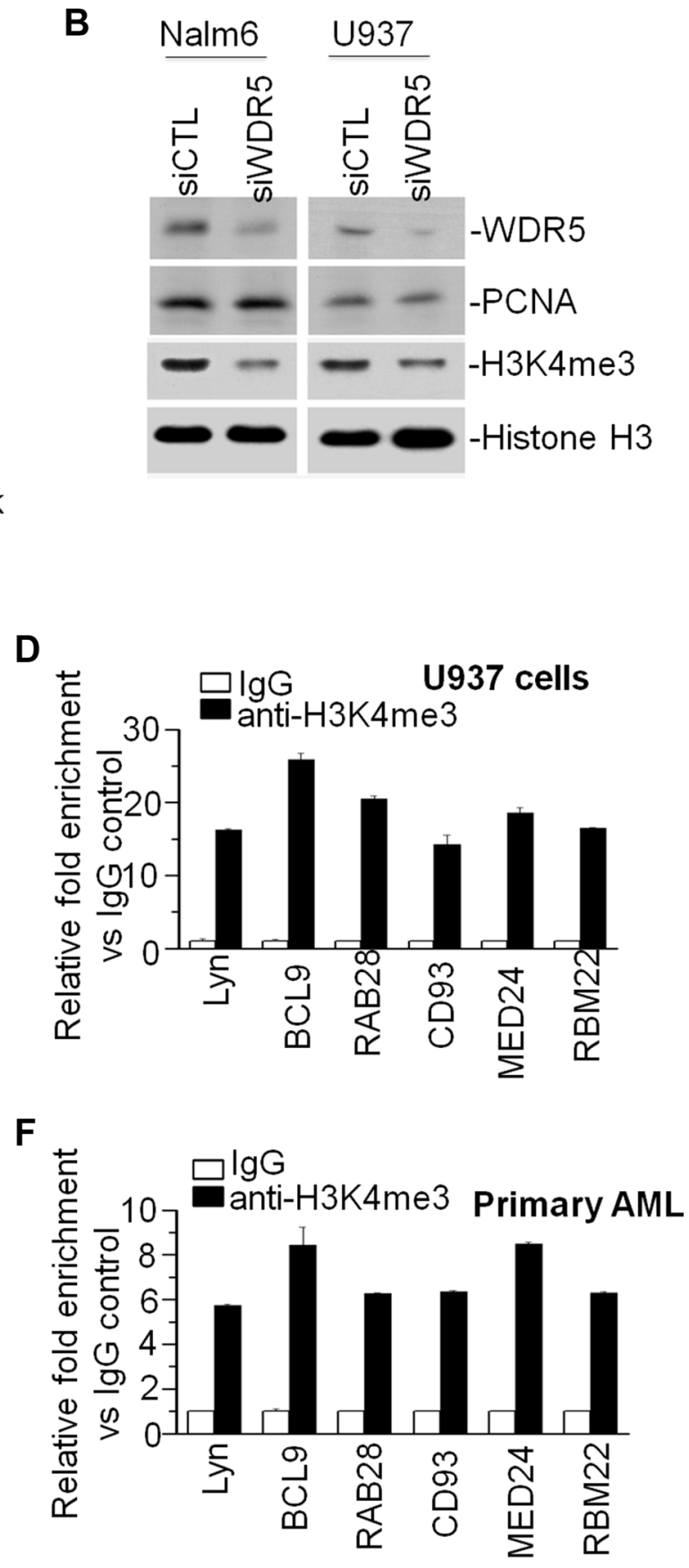

Figure 5: WDR5 associates with MLL in leukemia cells and global accumulation of H3K4me3 around the WDR5 binding peaks (A). Distribution of H3K4me3 peaks relative to the center of WDR5 peak in RS4;11 and THP-1 cells. Graphed is the frequency of H3K4me3 in all WDR5 peaks, over a $1 \mathrm{~kb}$ span. (B) Effect of WDR5 knockdown on H3K4me3 level. (C-F) H3K4me3 enrichment in the promoter region of WDR5 targets in cell lines, Nalm6 (C) and U937 (D) cells, and primary B-ALL (E) and AML (F) cells. 
A

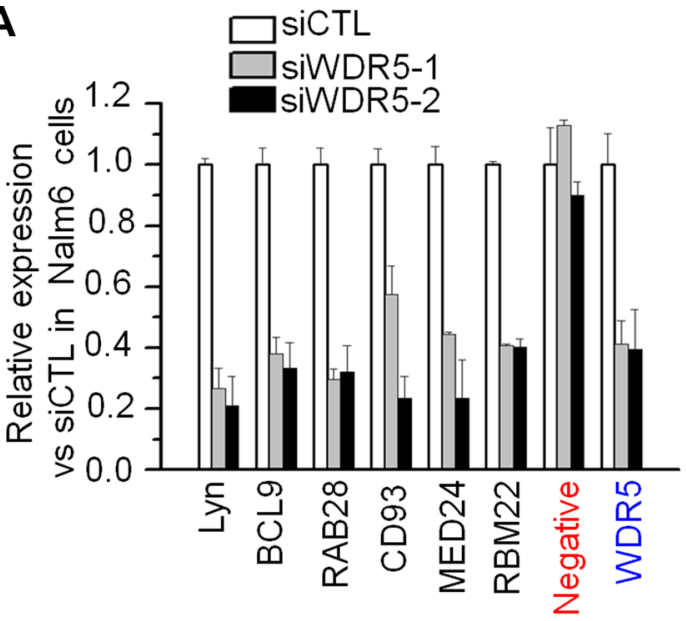

B

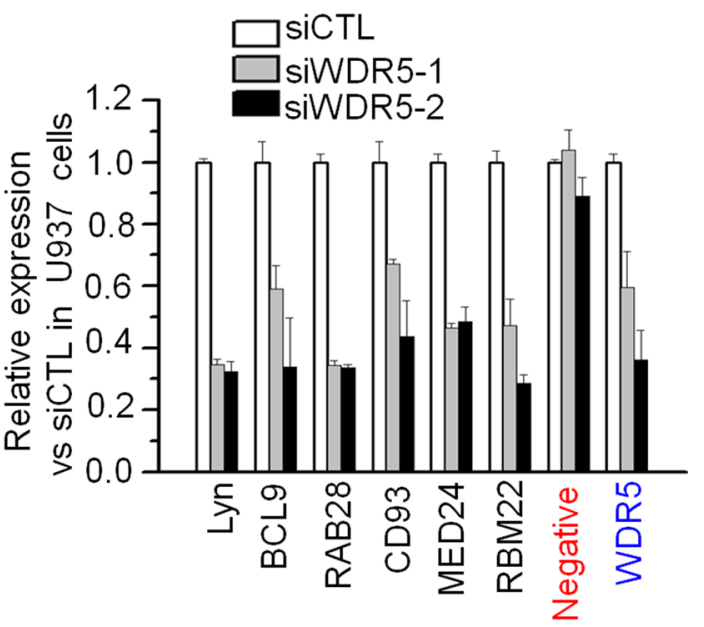

C

qChIP Primers at Promoter of WDR5 Targets

$\begin{array}{cccccc}P 1 & \frac{P 2}{T} & \frac{P 3}{T} & \frac{P 4}{T} & \frac{P 5}{T} & \frac{P 6}{T} \\ -2000 & -1500 & -1000 & -500 & 0 & 500 b p \\ T S S & \end{array}$

D

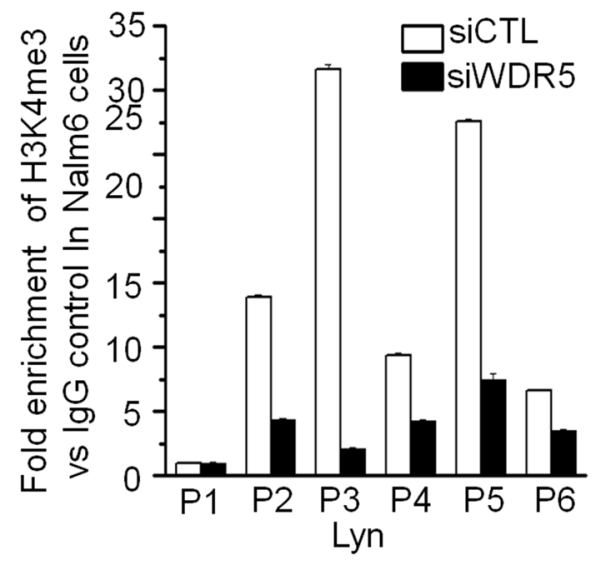

$\mathbf{F}$

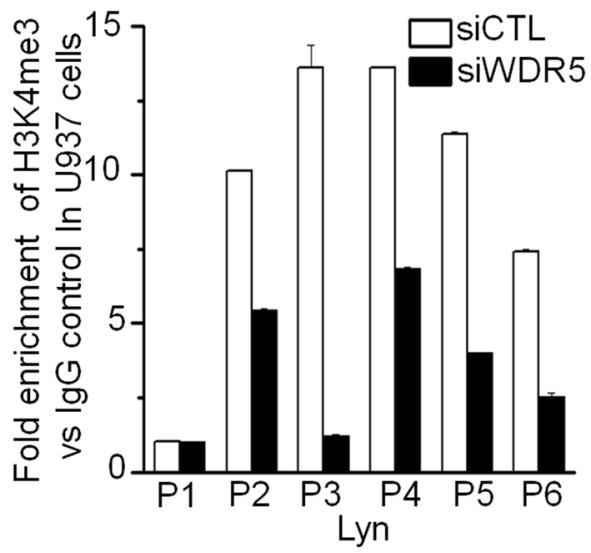

$\mathbf{E}$

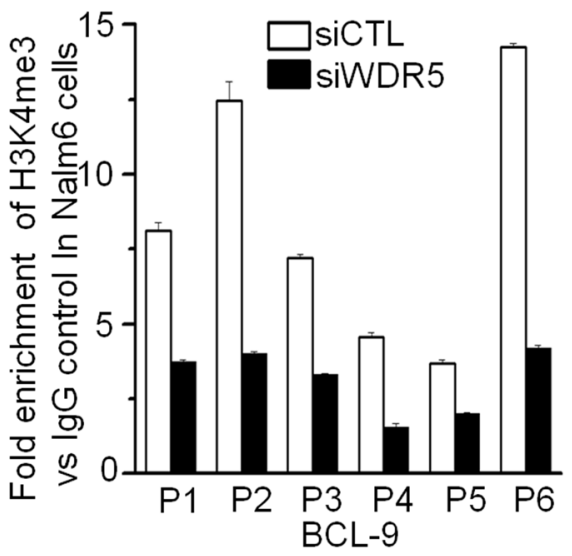

G

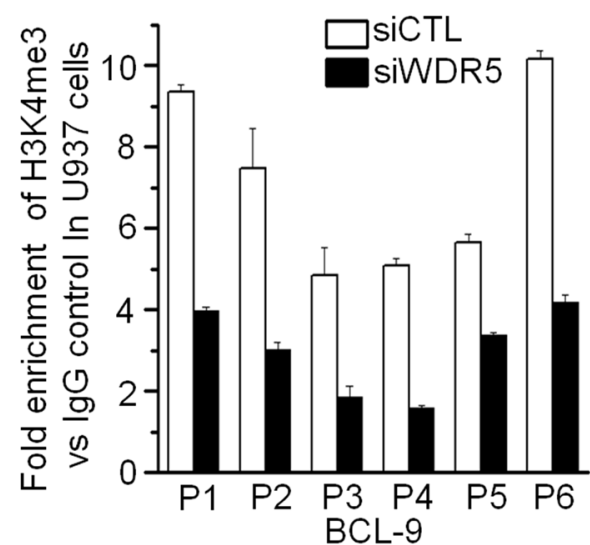

Figure 6: WDR knockdown suppresses the expression of its targets and H3K4me3 binding to the promoter of its targets. (A-B) The expression of WDR5 targets inn Nalm6 (A) and U937 (B) cells treated with siWDR5. Cells treated with siWDR-1 or -2 shRNA and scramble shRNA (siCTL) for two days, total RNA was isolated for gene expression by qPCR. (C) Location of the primers for PCR of promoter of Lyn and BCL9. (D-F) H3K4me3 binding on Lyn and BCL9 in Nalm6 (D, E) and U937 (F, G) cells. Cells treated with siWDR shRNA and siCTL for two days, qChIP assay was performed for the binding with anti-H3K4me3 antibody. 
It has been reported that the existence of a TK network composed of the tyrosine AXL, Lyn and SYK, promotes cell resistance to nilotinib treatment and drives $\mathrm{Bcr}-\mathrm{Abl}$ independent CML cell proliferation. The up-regulation of Lyn and other TKs is observed in TKI-resistant CML cells [34, 43] and high Lyn expression in leukemia $[41,44]$. Lyn plays a critical role in oncogenesis of AML [45]. Lyn is also responsible for anti-apoptosis in the cancer cells [46]. We observed the positive correlation of WDR5 expression with Lyn in the cohort study of ALL and AML patients, and also WDR5 high expression significantly appeared in $\mathrm{Ph}(+)$ patients. WDR5 knockdown induced the down-regulation of Lyn, indicating WDR5-mediated transcriptional activation of Lyn may play important roles in oncogenesis as a downstream target of WDR5 high expression in acute ALL and AML.

Other WDR5 targets, such as BCL9, the antiapoptosis BCL-2 family member, is a proto-oncogene previously characterized as co-activator of $\mathrm{Wnt} / \mathrm{B}_{\text {- }}$ catenin signaling, for mammary tumorigenesis in mice and humans [47]. WDR5 target RAB28, member of the Ras oncogene family, is reported to be differentially expressed in swine melanoma [48]. Another WDR5 target, MED24 is a component of the mediator complex , a transcriptional coactivator complex requires for the expression of almost all genes. It is reported that MED24 is overexpressed in breast cancer cells [49]. WDR5 target RBM22 is an RNA binding protein that may play a role in cell division and may be involved in pre-mRNA splicing. We found that WDR5 expression is positively correlated with expression of BCL9, MED24 and RAB28 in the cohort study of ALL and AML patients. Notably, WDR5 knockdown dramatically suppress expression of these targets in the leukemia cells. These data revealed that high expression of WDR5 is critical for transcriptional activation of these targets, which may be further responsible for the onset of oncogenesis and cell proliferation in leukemia. Moreover, WDR5 is reported to be involved in cell differentiation and reprogram of stem cells [57]; we did observe some WDR5 targets involving cell differentiation, therefore the effect of WDR5 knockdown on differentiation of the ALL and AML cells will be further clarified.

In summary, we identified that WDR5 is highly expressed in adult ALL and AML, and showed its correlation with high-risk leukemia. We also identified the WDR5 binding profile in leukemia cells and found WDR5 bindings globally co-localized with H3K4me3 in leukemia cells. Our finding revealed the WDR5 knockdown results in the proliferation arrest and apoptosis of leukemia cells, and also decreased the expression of its targets through loss of H3K4me3. Our data reveal that WDR5 has oncogenic effects and WDR5mediated H3K4 methylation may play an important role in leukemogenesis.

\section{MATERIALS AND METHODS}

\section{Patients and samples}

The 151 patients' BM samples [90 male, 61 female; median age 32 (14-77) years old] with AML (91 patients) and ALL (40 B-ALL, 20 T-ALL), and the 30 volunteers' BM samples for control were collected between June 2008 and June 2014 at the First Affiliated Hospital of Nanjing Medical University. The ALL and AML diagnosis was made according to the cytogenetic, morphologic, Immunophenotypic and molecular criteria of WHO Diagnosis and Classification of ALL (2008). The written informed consent was provided by all patients and volunteers in accordance with the Declaration of Helsinki before enrollment in the study. The cohort study was also approved by the Institutional Review Board of the Nanjing Medical University. Cytogenetic and molecular analyses as previously reported.

\section{Cytogenetic and molecular analyses}

Conventional cytogenetic analysis was performed at the time of diagnosis by using unstimulated short-term cultures according to the recommendations of the International System for Human Cytogenetic Nomenclature (ISCN). At least 20 BM metaphase cells were analyzed for each sample.

The flow cytometry was performed to do immunophenotypic analyses on fresh pretreatment BM samples. The cell-surface antigen was defined as positive when fluorescence intensity of at least $20 \%$ of cells exceeded fluorescence of negative control as previously described $[45,46]$.

Risk status in AML patients was classified by cytogenetics and molecular abnormalities with National Comprehensive Cancer Network (NCCN) Guideline Version1-2015. Favorable-risk: $\operatorname{inv}(16)$ or $t(16 ; 16)$; $\mathrm{t}(8 ; 21)$; $\mathrm{t}(15 ; 17)$; normal cytogenetics with NPM1 mutation or isolated CEBPA mutation in the absence of FLT3. Intermediate-risk: Normal cytogenetics; +8 ; $\mathrm{t}(9 ; 11)$; Other non-defined; $\mathrm{t}(8 ; 21)$, inv (16), $\mathrm{t}(16 ; 16)$ with c-KIT mutation. Poor-risk: Complex ( 3 abnormal clones); -5, 5q-, -7, 7q-; $11 \mathrm{q} 23$ - non $\mathrm{t}(9 ; 11) ; \operatorname{inv}(3), \mathrm{t}(3 ; 3) ; \mathrm{t}(6 ; 9) ; \mathrm{t}(9 ; 22)$; Normal cytogenetics with FLT3-ITD mutation.

\section{Cell culture, reagents, plasmid construction, retroviral gene transfer}

RS4;11, U937, THP-1 and Nalm6 cells were obtained from American Type Culture Collection (ATCC, Manassas, VA) and cultured in RPMI 1640 medium (Cellgro) supplemented with 10\% fetal bovine serum (Hyclone). Cells were incubated at $37^{\circ} \mathrm{C}$ in a humidified atmosphere of $5 \% \mathrm{CO}_{2}$.

Primary leukemia cells were obtained from the Anonymous patient with B-ALL and AML at First 
Affiliated Hospital of Nanjing Medical University, in compliance with Institutional Review Board regulations.

\section{ChIP-seq assay}

ChIP-seq assays for WDR5 and H3K4me3 in leukemia cells were performed as previously reported [50-53] and as described for qChIP assay. For ChIPseq library, cells were cross-linked for $10 \mathrm{~min}$ in PBS containing $1 \%$ formaldehyde and reaction was stopped by adding glycine. Cell pellets were flash frozen and stored at $-80^{\circ} \mathrm{C}$. Chromatin was fragmented using the Bioruptor sonicator (Diagenode) for $30 \mathrm{~min}$ (30s pulses, 30s pauses in between) (for WDR5) or using Micrococcal nuclease (for H3K4me3) to produce fragments $\sim 400 \mathrm{bp}$ in size. ChIP assays were performed by incubation of the chromatin with anti-WDR5 antibodies (ab56919) or H3K4me3 antibody (ab8580), which was pre-coated onto Goat-anti-rabbit IgG Dyneabeads (Invitrogen). Following overnight incubation at $4{ }^{\circ} \mathrm{C}$, protein/DNA complexes were extensively washed and eluted. The ChIPed DNA was de-crosslinked, digested with proteinase $\mathrm{K}$, extracted with phenol/chloroform, and then treated with RNaseA. Finally, the DNA was purified using the QIAquick PCR Purification kit (QIAGEN). ChIP-seq libraries were created using ChIP-seq DNA sample prep kit (Illumina), size-selected and the 200-400 bp fraction was extracted and purified. Libraries were sequenced at Genomics Center BTG company (Beijing, China). Sequence fastq files were aligned to the UCSC human genome assembly HG19 using the Eland application, allowing no more than two mismatches per sequence. Only sequences aligning uniquely to the human genome were used to identify peaks. Peaks were called using MACS with default parameters.

ChIP-Seq data are accessible on GEO with an access number of http://www.ncbi.nlm.nih.gov/geo/query/acc.cgi ?token=ibghmioodfqdlqx\&acc=GSE72864.

\section{Bioinformatic analysis of ChIP-seq data}

Annotation of the peaks, distribution of peaks in different gene regulatory regionsand relation of WDR5 peaks and $\mathrm{H} 3 \mathrm{~K} 4 \mathrm{me} 3$ peaks are analyzed as our previous reports $[52,53]$.

\section{Annotation of the peaks}

Peak annotation with associated genes was retrieved with a Perl script. In this script program, the peak information was input from the MCAS output peak files in "COD" format. Then, the nearest gene to each peak and associated locations (gene start, gene end, 5'UTR, 3'UTR, exon and intron) in the human genome was identified using the built-in program. The gene names from HGNC [54] were also input and passed. The output data file includes the integrated information of peaks, genes and annotations.

\section{Distribution of peaks in different gene regulatory regions}

The number of peaks in different gene regulatory regions (e.g. promoter and intergenic regions) was calculated using a Perl script and then the distribution of the peaks in each treatment was depicted in a Figure in a column chart or a pie graph using Microsoft Excel. The peaks passing each position in relation to TSS (Transcriptional Start Site) and TES (Transcriptional End Site) was also counted by a Perl script program. In this program, the maximum number of peaks at a position was also recorded. The percentage of the number of peaks passing each position over the maximum number of peaks at a position was computed and then output into a tabdelimited text file. Finally, the output data was plotted using the Microsoft Excel or Origin software package.

\section{Relation of WDR5 peaks and H3K4me3 peaks}

The H3K4me3 peaks were mapped onto the WDR5 peaks at distances of $50 \mathrm{bp}, 100 \mathrm{bp}, 200 \mathrm{bp}, 500 \mathrm{bp}, 1 \mathrm{~kb}$, $2 \mathrm{~kb}, 3 \mathrm{~kb}, 4 \mathrm{~kb}$ and $5 \mathrm{~kb}$ from the centers of the H3K4me 3 peaks to the center of the WDR5 peak using a Perl script program.

The H3K4me3 densities per 100 WDR5 peak/kb were calculated using the equation:

$\mathrm{HMd}=\left(\mathrm{Y}_{\mathrm{i}}-\mathrm{Y}_{\mathrm{i}-1}\right) * 100 /\left[\left(\mathrm{X}_{\mathrm{i}}-\mathrm{X}_{\mathrm{i}-1}\right) * \mathrm{M}\right]$

Where:

HMd represents $\mathrm{H} 3 \mathrm{~K} 4 \mathrm{me} 3$ density

$\mathrm{Y}_{\mathrm{i}}$ is the peak number of $\mathrm{H} 3 \mathrm{~K} 4 \mathrm{me} 3 \mathrm{i}$.

$\mathrm{X}_{\mathrm{i}}$ is studying distance from a $\mathrm{H} 3 \mathrm{k} 4 \mathrm{me} 3$ peak center to a WDR5 peak center

$\mathrm{M}$ is the peak number of WDR5 peaks.

The resulting data were plotted into graphs using the Original software package.

\section{Quantitative chromatin immunoprecipitation (qChIP)}

The qChIP assay was done as previous reported $[52,53]$. Briefly, $1 \times 10^{7}$ cells were collected and crosslinked in cross-link solution containing $1 \%$ formaldehyde for $10 \mathrm{~min}$ on ice. The reaction was stopped by adding glycine to a final concentration of $0.125 \mathrm{M}$. The ChIP samples were prepared as follows: cells per condition were treated with solution I ( $50 \mathrm{mM}$ Hepes $\mathrm{KOH}, \mathrm{pH} 7.5$, $140 \mathrm{mM} \mathrm{NaCl}, 1 \mathrm{mM}$ EDTA, 10\% Glycerol, $0.5 \%$ NP- 40, $0.25 \%$ Triton $\mathrm{X}-100$, protease inhibitor) with rotation at $4^{\circ} \mathrm{C}$ for $10 \mathrm{~min}$. The pelleted cells further treated with solution II $0.2 \mathrm{M} \mathrm{NaCl}, 1 \mathrm{mM}$ EDTA pH 8.0, $0.5 \mathrm{mM}$ EGTA pH 8.0, $10 \mathrm{mM}$ Tris $\mathrm{pH}$ 8.0, protease inhibitor) with rotation for $10 \mathrm{~min}$ at room temperature. The chromatin was fragmented in solution III (1 mM EDTA $\mathrm{pH} 8.0$, $0.5 \mathrm{mM}$ EGTA pH 8.0, $10 \mathrm{mM}$ Tris $\mathrm{pH} 8.0$, protease inhibitor) with a Bioruptor (Diagenode,) for $30 \mathrm{~min}(30 \mathrm{~s}$ 
pulses, $90 \mathrm{~s}$ pauses) to obtain an average size of $400 \mathrm{bp}$ and the chromatin was centrifuged at 4000 RPM for $10 \mathrm{~min}$ at $4^{\circ} \mathrm{C}$ and added with $10 \%$ glycerol. The WDR5 (ab56919) and H3K4me3 (ab8580) antibodies and normal rabbit IgG (ab171870) as control [53] pre-coated onto Goat-anti-rabbit IgG Dyneabeads (Invitrogen) are used and incubated with chromatin overnight at cold room. Protein/DNA complexes were captured with a Magnetic Particle Concentrator (Invitrogen). Crosslinks were reversed. Samples were treated with proteinase $\mathrm{K}$ and RNaseA. DNA was then recovered using the QIAquick PCR Purification kit (QIAGEN). Enrichment of the ChIP sample over input was evaluated by qPCR with three or more replicates, using specific primers in the promoter region of WDR5 target (Supplementary Table S4). Relative concentration of the qPCR product was presented as the fold change of the level of DNA-WDR5 samples in comparison to controls.

\section{Real Time-PCR}

Total RNA was isolated using the RNeasy Mini Kit (QIAGEN). A $1 \mu \mathrm{g}$ aliquot of RNA was reverse transcribed using a SuperScript ${ }^{\mathrm{TM}}$ First-Strand Synthesis System for RT-PCR Kit (Invitrogen). qRT-PCR was performed with qSTAR SYBR Master Mix (OriGene) using a StepOne Plus real-time PCR system (Applied Biosystems). Each experiment was performed in triplicate.

In order to quantitate gene expression value in patients' samples, template standards and primers against Homo sapiens gene WDR5 (HK204310, OriGene, USA) and Homo sapiens housekeeping gene GAPDH, HK203273, OriGene, USA) were obtained from OriGene Technologies (Rockville, $\mathrm{MD}$ ). Gene expression values of the genes of interest (GOI) were achieved in each patient by a formula obtained with a scatter graph of the $\mathrm{Ct}$ values from the serial dilutions of template standard following manufacturer's instruction and as previously reported $[40,44]$. The expression level of GOI was subsequently normalized to the housekeeping gene, expressed as gene expression value of GOI/GAPDH.

All the patients were divided into high and low WDR5 expression groups (Q3-4 vs Q1-2) and the cutoffwas determined by SPSS 17.0. Statistical analysis with analysis of variance (ANOVA) showed that the difference of $W D R 5$ expression in the two groups was very much significant $(P<0.0001)$.

The qPCR for expression of WDR5 targets in the WDR5 knockdown cells was performed and the results were normalized to those obtained with 18sRNA and presented as fold induction over vector controls. Primers for the qPCR are listed in Supplementary Table S4. Primer for $18 s R N A$, Sense: 5'-GTAACCCGTTGAACCCCATT3', Antisense: 5'- CCATCCAATCGGTAGTAGCG-3'.

\section{Co-Immunoprecipitation}

THP-1 cells were homogenized in radioimmune precipitation assay buffer containing $25 \mathrm{mM}$ Tris- $\mathrm{HCl}$ (pH 7.4), $150 \mathrm{mM} \mathrm{NaCl}, 60 \mathrm{mM}$ n-octyl-D-glucoside, $1 \%$ Triton X-100, 2 mM PMSF, and a protease inhibitor tablet $/ 50 \mathrm{ml}$. The homogenate was centrifuged to remove insoluble debris. $400 \mu \mathrm{g}$ of supernatant was used for each reaction and was precleared with protein A/G-Sepharose beads (Pierce). The precleared supernatant was incubated in primary antibody overnight at $4^{\circ} \mathrm{C}$, and proteinantibody complexes were recovered using recombinant protein A/G-Sepharose (Pierce). As a negative control, isotype control IgG was used. Cell lysates were separated on precast 10-20\% SDS-PAGE gels and immunoblotted as described previously [46].

\section{WDR5 shRNA knockdown and Western blot}

The Nalm6 and U937 cells were transiently transfected with human WDR5 shRNA constructs in the GFP vector (pGFP-v-RS) (Origene) using the Neon Transfection System (Invitrogen). The 29-mer scrambled shRNA cassette in the pGFP-VRS vector was also used as a control. After transfection for 2 days, cells with transfection efficiency above $\sim 80 \%$ and cell viability greater than $95 \%$, were harvested for cell proliferation and apoptosis assay, and also for total RNA isolation. Knockdown of WDR5 was confirmed by measurement of WDR 5 mRNA level with qPCR. Primers: WDR5-F: 5'- CC GAACGGCAAATACATCCT -3', WDR5-R: 5'- TGTA GTCCCAGAGCTTCAGAGTGT -3'.

WDR5 protein level was also determined by western blot with anti-WDR5 antibody in the knockdown cells and scramble shRNA control. PCNA protein level was also examined as loading control.

\section{Histone extraction}

Histone extraction was performed using the Abcam histone extraction protocol (www.abcam.com). The protein was quantified using the Bradford assay and used for western blot analysis.

\section{Proliferation and cytotoxicity assays}

The colorimetric WST-1 cell proliferation assay (Roche Applied Science; 11644807001) was performed in 96-well white clear bottom plates (Costar, 3610) in quadruplicate, according to manufacturer's instructions $[52,54]$. Absorbance at $440 \mathrm{~nm}$ (reflects number of viable cells) was measured using a BioTek Synergy Mx plate reader. Cytotoxicity assays were performed in triplicpate 
by incubating $1.0 \times 10^{6}$ cells per well 24 -well plate in the presence or absence of drugs in a final volume of $1 \mathrm{ml}$. Aliquots of cells were harvested at indicated time periods and hemocytometer count using Trypan blue exclusion was used to obtain viable cell counts.

\section{Determination of apoptosis by flow cytometry}

Apoptosis was measured by staining cells with PE Annexin V and 7-AAD [49, 52]. Cells were analyzed and quantified by flow cytometry (MODFit). Nalm6 and U937 cells were transfected with WDR5 shRNA or scramble shRNA as control, respectively. Two days after the transfection, the cells were harvested, washed and then stained with fluorochrome-conjugated Annexin $\mathrm{V}$ following the manufactory's Manual (Bioscience). Annexin $\mathrm{V}$ and 7-AAD negative were identified as live cells, whereas 7-AAD positive alone were dead cells. Cells which were positive for Annexin V but were 7-AAD negative were identified as early apoptosis. Cells which were both Annexin-V and 7-AAD positive were identified as cells in late apoptosis. The ratio of the apoptotic cells included both early and late apoptotic cells.

\section{Statistical analysis}

Patients were divided into high and low WDR5 expression groups (Q3-4 vs Q1-2) [55, 56]. For quantitative parameters, overall differences between the cohorts were evaluated using a Mann - Whitney $U$-test. For qualitative parameters, overall group differences were analyzed using a $\chi^{2}$ test. All statistical analyses were performed using the SPSS 17.0 and $P<0.05$ was considered statistically significant.

The experimental data are shown as the mean value with bars representing the standard error of the mean (S.E.M.). Determinations of statistical significance were performed using a Student $t$-test for comparisons of two groups or using analysis of variance (ANOVA) for comparing multiple groups. The $P<0.05$ was considered statistically significant. All data fit for normal distribution with $t$ or $u$ test, and the data for ANOVA analysis are homogeneity data

\section{ACKNOWLEDGMENTS AND FUNDING}

We thank Justin Olson for his English grammar correction. This work is supported by The National Natural Science Foundation of China (81270613,30973376); Jiangsu Province Key Medical Talents (RC2011077); The Scientific Research Foundation for the Returned Overseas Chinese Scholars, State Education Ministry (39th); China Postdoctoral Science Foundation (20090461134 ); Special grade of the financial support from China Postdoctoral Science Foundation (201003598); The Six Great Talent Peak Plan of Jiangsu (2010-WS-024); The Scientific
Research Foundation for the Returned Overseas Chinese Scholars, Nanjing Municipal Bureau of Personnel (2009); Southeast University Basic Research fund (2242016 K40143) (to Z.G.); also supported partially by the Four Diamonds Fund of the Pennsylvania State University, College of Medicine, and the John Wawrynovic Leukemia Research Scholar Endowment ( to S.D. and C.S.).

\section{CONFLICTS OF INTEREST}

The authors declare no competing financial interests.

\section{Author's contributions}

Z.G., E.S., J. L. and C.S. performed experiments and analyzed data; C.S., Z.G. and S.D. designed and supervised data analysis; Y. K. did the data analysis; C.S. and Z.G. wrote the manuscript.

\section{REFERENCES}

1. Marcucci G, Yan P, Maharry K, Frankhouser D, Nicolet D, Metzeler KH, Kohlschmidt J, Mrózek K, Wu YZ, Bucci D, Curfman JP, Whitman SP, Eisfeld AK, et al. Epigenetics meets genetics in acute myeloid leukemia: clinical impact of a novel seven-gene score. J Clin Oncol. 2014; 32:548-556.

2. Wong SH, Goode DL, Iwasaki M, Wei MC, Kuo HP, Zhu L, Schneidawind D, Duque-Afonso J, Weng Z, Cleary ML. The H3K4-Methyl Epigenome Regulates Leukemia Stem Cell Oncogenic Potential. Cancer Cell. 2015; 28:198-209.

3. Muntean AG, Hess JL. The pathogenesis of mixed-lineage leukemia. Annual review of pathology. 2012; 7:283-301.

4. Reddy KS, Parsons L, Mak L, Dighe P, Saphner T, Crow MK, Scott M. Segmental amplification of 11q23 region identified by fluorescence in situ hybridization in four patients with myeloid disorders: a review. Cancer genetics and cytogenetics. 2001; 126:139-146.

5. Poppe B, Vandesompele J, Schoch C, Lindvall C, Mrozek K, Bloomfield CD, Beverloo HB, Michaux L, Dastugue N, Herens C, Yigit N, De Paepe A, Hagemeijer A, et al. Expression analyses identify MLL as a prominent target of 11q23 amplification and support an etiologic role for MLL gain of function in myeloid malignancies. Blood. 2004; 103:229-235.

6. Maitta RW, Cannizzaro LA, Ramesh KH. Association of MLL amplification with poor outcome in acute myeloid leukemia. Cancer Genet Cytogenet. 2009; 192:40-43.

7. Ono R, Nakajima H, Ozaki K, Kumagai H, Kawashima T, Taki T, Kitamura T, Hayashi Y, Nosaka T. Dimerization of MLL fusion proteins and FLT3 activation synergize to induce multiple-lineage leukemogenesis. The Journal of clinical investigation. 2005; 115:919-929.

8. Zhu J, Sammons MA, Donahue G, Dou Z, Vedadi M, Getlik M. Barsyte-Lovejoy D, Al-awar R, Katona BW, 
Shilatifard A, Huang J, Hua X, Arrowsmith CH, et al. Gainof-function $\mathrm{p} 53$ mutants co-opt chromatin pathways to drive cancer growth. Nature. 2015; 525:206-11.

9. de Boer J, Walf-Vorderwulbecke V, Williams O. In focus: MLL-rearranged leukemia. Leukemia. 2013; 27:1224-1228.

10. Ayton PM, Cleary ML. Molecular mechanisms of leukemogenesis mediated by MLL fusion proteins. Oncogene. 2001; 20:5695-5707.

11. Bernt KM, Armstrong SA. Targeting epigenetic programs in MLL-rearranged leukemias. Hematology/the Education Program of the American Society of Hematology American Society of Hematology Education Program. 2011; 2011:354-360.

12. Dou Y, Hess JL. Mechanisms of transcriptional regulation by MLL and its disruption in acute leukemia. International journal of hematology. 2008; 87:10-18.

13. Mueller D, Bach C, Zeisig D, Garcia-Cuellar MP, Monroe S, Sreekumar A, Zhou R, Nesvizhskii A, Chinnaiyan A, Hess JL, Slany RK. A role for the MLL fusion partner ENL in transcriptional elongation and chromatin modification. Blood. 2007; 110:4445-4454.

14. Milne TA, Briggs SD, Brock HW, Martin ME, Gibbs D, Allis CD, Hess JL. MLL targets SET domain methyltransferase activity to Hox gene promoters. Molecular cell. 2002; 10:1107-1117.

15. Muntean AG, Tan J, Sitwala K, Huang Y, Bronstein J, Connelly JA, Basrur V, Elenitoba-Johnson KS, Hess JL. The PAF complex synergizes with MLL fusion proteins at HOX loci to promote leukemogenesis. Cancer cell. 2010; 17:609-621.

16. Jo SY, Granowicz EM, Maillard I, Thomas D, Hess JL. Requirement for Dot11 in murine postnatal hematopoiesis and leukemogenesis by MLL translocation. Blood. 2011; 117:4759-4768.

17. Krivtsov AV, Armstrong SA. MLL translocations, histone modifications and leukaemia stem-cell development. Nature reviews Cancer. 2007; 7:823-833.

18. Okada Y, Feng Q, Lin Y, Jiang Q, Li Y, Coffield VM, Su L, $\mathrm{Xu} \mathrm{G}$, Zhang Y. hDOT1L links histone methylation to leukemogenesis. Cell. 2005; 121:167-178.

19. Lin C, Smith ER, Takahashi H, Lai KC, Martin-Brown S, Florens L, Washburn MP, Conaway JW, Conaway RC, Shilatifard A. AFF4, a component of the ELL/P-TEFb elongation complex and a shared subunit of MLL chimeras, can link transcription elongation to leukemia. Molecular cell. 2010; 37:429-437.

20. Ohyashiki K, Kocova M, Ryan DH, Rowe JM \& Sandberg A A Secondary acute myeloblastic leukemia with a $\mathrm{Ph}$ translocation in a treated Wegener's granulomatosis. Cancer Genet Cytogenet. 1986; 19:331-3.

21. Thiel AT, Blessington P, Zou T, Feather D, Wux, Yan J, Zhang H, Liu Z, Ernst P, Koretzky GA, Hua X. MLL-AF9induced leukemogenesis requires coexpression of the wildtype Mll allele. Cancer Cell. 2010; 17:148-59.
22. Steward MM, Lee JS, O'Donovan A, Wyatt M, Bernstein BE, Shilatifard A. Molecular regulation of H3K4 trimethylation by ASH2L, a shared subunit of MLL complexes. Nature structural \& molecular biology. 2006; 13:852-854.

23. Wysocka J, Swigut T, Milne TA, Dou Y, Zhang X, Burlingame AL, Roeder RG, Brivanlou AH, Allis CD. WDR5 associates with histone $\mathrm{H} 3$ methylated at $\mathrm{K} 4$ and is essential for $\mathrm{H} 3 \mathrm{~K} 4$ methylation and vertebrate development. Cell. 2005; 121:859-872.

24. Dou Y, Milne TA, Ruthenburg AJ, Lee S, Lee JW, Verdine GL, Allis CD, Roeder RG. Regulation of MLL1 H3K4 methyltransferase activity by its core components. Nature structural \& molecular biology. 2006; 13:713-719.

25. Trievel RC, Shilatifard A. WDR5, a complexed protein. Nat Struct Mol Biol. 2009; 16:678-680.

26. Wu M, Shu HB. MLL1/WDR5 complex in leukemogenesis and epigenetic regulation. Chinese journal of cancer. 2011; 30:240-246.

27. Migliori V, Mapelli M, Guccione E. On WD40 proteins: propelling our knowledge of transcriptional control? Epigenetics. 2012; 7:815-822.

28. Thomas LR, Foshage AM, Weissmiller AM, Tansey WP. The MYC-WDR5 Nexus and Cancer. Cancer Res. 2015; 75:4012-5.

29. Patel A, Dharmarajan V, Cosgrove MS. Structure of WDR5 bound to mixed lineage leukemia protein-1 peptide. J Biol Chem. 2008; 283:32158-32161.

30. Song JJ, Kingston RE. WDR5 interacts with mixed lineage leukemia (MLL) protein via the histone H3-binding pocket. J Biol Chem. 2008; 283:35258-35264.

31. Cao F, Townsend EC, Karatas H, Xu J, Li L, Lee S, Liu L, Chen Y, Ouillette P, Zhu J, Hess JL, Atadja P, Lei M, et al. Targeting MLL1 H3K4 methyltransferase activity in mixedlineage leukemia. Molecular cell. 2014; 53:247-261.

32. Grebien, F, Vedadi M, Getlik M, Giambruno R, Grover A, Avellino R, Skucha A, Vittori S, Kuznetsova E, Smil D, Barsyte-Lovejoy D, Li F, Poda G, et al. Pharmacological targeting of the Wdr5-MLL interaction in $\mathrm{C} / \mathrm{EBP} \alpha$ N-terminal leukemia. Nat Chem Biol. 2015; 11:571-8.

33. Kim JY, Banerjee T, Vinckevicius A, Luo Q, Parker JB, Baker MR, Radhakrishnan I, Wei JJ, Barish GD, Chakravarti D. A role for WDR5 in integrating threonine 11 phosphorylation to lysine 4 methylation on histone $\mathrm{H} 3$ during androgen signaling and in prostate cancer. Mol Cell. 2014; 54:613-625.

34. Chen R, Chen B. The role of dasatinib in the management of chronic myeloid leukemia. Drug Des Devel Ther. 2015; 9:773-779.

35. Sun Y, Bell JL, Carter D, Gherardi S, Poupos RC, Milazzo G, Wong JW, Al-Awar R, Tee AE, Liu PY, Liu B, Atmadibrata B, Wong M, et al. WDR5 Supports an N-Myc Transcriptional Complex That Drives a Protumorigenic Gene Expression Signature in Neuroblastoma. Cancer Res. 2015; 75:5143-54. 
36. Chen X, Xie W, Gu P, Cai Q, Wang B, Xie Y, Dong W, He W, Zhong G, Lin T, Huang J. Upregulated WDR5 promotes proliferation, self- renewal and chemoresistance in bladder cancer via mediating H3K4 trimethylation. Sci Rep. 2015; 5:8293 .

37. Eissenberg JC, Shilatifard A. Histone H3 lysine 4 (H3K4) methylation in development and differentiation. Dev Biol. 2010; 339:240-249.

38. Krogan NJ, Dover J, Khorrami S, Greenblatt JF, Schneider J, Johnston M, Shilatifard A. COMPASS, a histone H3 (Lysine 4) methyltransferase required for telomeric silencing of gene expression. J Biol Chem. 2002; 277:10753-10755.

39. Contri A, Brunati AM, Trentin L, Cabrelle A, Miorin M, Cesaro L, Pinna LA, Zambello R, Semenzato G, DonellaDeana A. Chronic lymphocytic leukemia B cells contain anomalous Lyn tyrosine kinase, a putative contribution to defective apoptosis. J Clin Invest. 2005; 115:369-378.

40. Trentin L, Frasson M, Donella-Deana A, Frezzato F, Pagano MA, Tibaldi E, Gattazzo C, Zambello R, Semenzato G, Brunati AM. Geldanamycin-induced Lyn dissociation from aberrant Hsp90-stabilized cytosolic complex is an early event in apoptotic mechanisms in B-chronic lymphocytic leukemia. Blood. 2008; 112:4665-4674.

41. Zonta F, Pagano MA, Trentin L, Tibaldi E, Frezzato F, Gattazzo C, Martini V, Trimarco V, Mazzorana M, Bordin L, Semenzato G, Brunati AM. Lyn-mediated procaspase 8 dimerization blocks apoptotic signaling in B-cell chronic lymphocytic leukemia. Blood. 2014; 123:875-883.

42. Zonta F, Pagano MA, Trentin L, Tibaldi E, Frezzato F, Trimarco V, Facco M, Zagotto G, Pavan V, Ribaudo G, Bordin L, Semenzato G, Brunati AM. Lyn sustains oncogenic signaling in chronic lymphocytic leukemia by strengthening SET-mediated inhibition of PP2A. Blood. 2015; 125:3747-3755.

43. Gioia R, Tregoat C, Dumas PY, Lagarde V, ProuzetMauleon V, Desplat V, Sirvent A, Praloran V, Lippert E, Villacreces A, Leconet W, Robert B, Vigon I, et al. CBL controls a tyrosine kinase network involving AXL, SYK and LYN in nilotinib-resistant chronic myeloid leukaemia. J Pathol 2015; 237:14-24.

44. Butrym A, Majewski M, Dzietczenia J, Kuliczkowski K, Mazur G. High expression of hematopoietic cell specific Lyn substrate-1 (HS1) predicts poor survival of B-cell chronic lymphocytic leukemia patients. Leuk Res. 2012; 36:876-880.

45. Dos Santos C, Demur C, Bardet V, Prade-Houdellier N, Payrastre B, Recher C. A critical role for Lyn in acute myeloid leukemia. Blood. 2008; 111:2269-2279.

46. Eldeeb MA, Fahlman RP. The anti-apoptotic form of tyrosine kinase Lyn that is generated by proteolysis is degraded by the N-end rule pathway. Oncotarget. 2014; 5:2714-2722. doi: 10.18632/oncotarget.1931.
47. Zatula N, Wiese M, Bunzendahl J, Birchmeier W, Perske C, Bleckmann A, Brembeck FH. The BCL9-2 protooncogene governs estrogen receptor alpha expression in breast tumorigenesis. Oncotarget. 2014; 5:6770-6787. doi: 10.18632/oncotarget.2252.

48. Okomo-Adhiambo M, Rink A, Rauw WM, GomezRaya L. Gene expression in Sinclair swine with malignant melanoma. Animal. 2012; 6:179-192.

49. Hasegawa N, Sumitomo A, Fujita A, Aritome N, Mizuta S, Matsui K, Ishino R, Inoue K, Urahama N, Nose J, Mukohara T, Kamoshida S, Roeder RG, et al. Mediator subunits MED1 and MED24 cooperatively contribute to pubertal mammary gland development and growth of breast carcinoma cells. Mol Cell Biol. 2012; 32:1483-1495.

50. Wang Z, Zang C, Rosenfeld JA, Schones DE, Barski A, Cuddapah S, Choi K, Farnham PJ, Bresnick EH. Combinatorial patterns of histone acetylations and methylations in the human genome. Nat Genet. 2008; 40:897-903.

51. Fujiwara T, O'Geen H, Keles S, Blahnik K, Linnemann AK, Kang YA, Choi K, Farnham PJ, Bresnick EH. Discovering hematopoietic mechanisms through genome-wide analysis of GATA factor chromatin occupancy. Mol Cell. 2009; 36:667-681.

52. Song C, Gowda C, Pan X, Ding Y, Tong Y, Tan BH, Wang H, Muthusami S, Ge Z, Sachdev M, Amin SG, Desai D, Gowda K, et al. Targeting casein kinase II restores Ikaros tumor suppressor activity and demonstrates therapeutic efficacy in high-risk leukemia. Blood. 2015; 126:1813-1822.

53. Song C, Pan X, Ge Z, Gowda C, Ding Y, Li H, Li Z, Yochum G, Muschen M, Li Q, Payne KJ, Dovat S. Epigenetic regulation of gene expression by Ikaros, HDAC1 and Casein Kinase II (CK2) in leukemia. Leukemia. 2015; doi: 10.1038/leu.2015.331.

54. Seal RL, Gordon SM, Lush MJ, Wright MW \& Bruford EA. genenames.org: the HGNC resources in 2011. Nucleic Acids Res. 2011; 39:D514-519.

55. Avet-Loiseau H, Godon C, Li JY, Daviet A, Mellerin MP, Talmant P, Harousseau JL, Bataille R. Amplification of the 11q23 region in acute myeloid leukemia. Genes, chromosomes \& cancer. 1999; 26:166-170.

56. Guo X, Zhang R, Liu J, Li M, Song C, Dovat S, Li J, Ge Z. Characterization of LEF1 High Expression and Novel Mutations in Adult Acute Lymphoblastic Leukemia. PLoS One. 2015; 10:e0125429.

57. Ang YS, Tsai SY, Lee DF, Monk J, Su J, Ratnakumar K, Ding J, Ge Y, Darr H, Chang B, Wang J, Rendl M, Bernstein E, et al. Wdr5 mediates self-renewal and reprogramming via the embryonic stem cell core transcriptional network. Cell. 2011; 145:183. 